Western University

Scholarship@Western

Department of Economics Research Reports

Economics Working Papers Archive

1990

\title{
Attachment to Home and Efficient Purchases of Population in a Fiscal Externality Economy
}

Arman Mansoorian

Gordon Myers

Follow this and additional works at: https://ir.lib.uwo.ca/economicsresrpt

Part of the Economics Commons

Citation of this paper:

Mansoorian, Arman, Gordon Myers. "Attachment to Home and Efficient Purchases of Population in a Fiscal Externality Economy."

Department of Economics Research Reports, 9010. London, ON: Department of Economics, University of Western Ontario (1990). 
RESEARCH REPORT 9010

ATTACHMENT TO HOME AND EFFICIENT PURCHASES OF POPULATION IN A FISCAL EXTERNALITY ECONOMY

\author{
by \\ Arman Mansoorian \\ and \\ Gordon Myers
}

August 1990

Department of Economics

University of Western Ontario

London, Ontario, Canada

Depariment of Economies Library

N6A 5 C2

AUG 231990

Iniversity of Westem onicis 


\title{
ATTACHMENT TO HOME AND EFFICIENT PURCHASES OF POPULATION IN A FISCAL EXTERNALITY ECONOMY
}

\author{
Arman Mansoorian \\ and \\ Gordon Myers
}

Department of Economics

The University of Western Ontario

London, Canada N6A 5C2

\begin{abstract}
This paper examines the efficiency properties of an economy characterized by strategically competing regions and individuals with varying degrees of attachment to home, in an otherwise standard fiscal externality setting. Regional authorities may make interregional transfers in purchasing preferred populations. However, there is a range of distributions of resources over which neither region makes transfers. Nevertheless, all equilibrium allocations resulting from the Nash behavior of regional authorities, including those that involve no transfers, are efficient. Therefore, in contrast to the standard conclusions of the fiscal externality literature, there is no efficiency role for a central authority.
\end{abstract}

JEL classifications: $941,324,325$

Without implication, we wish to thank John Burbidge, Peter Kuhn, and Jack Leach for very helpful comments. 


\section{INTRODUCTION}

There is a large literature on the efficiency properties of a system of competing regional jurisdictions. One strand of this broader literature is the fiscal externality literature, which examines the problems associated with the attainment of an efficient regional population distribution. The environment is one of free mobility, local public goods, local fixed factors and homogeneous individuals that work in their region of residence. The standard conclusion in the fiscal externality literature is that there is an externality associated with an individual's migration that generally leads to an inefficient distribution of population across regions. "Nonoptimality may occur because in moving from one region to another a migrant does not account for the effect of his moving on the tax price of the public good in the region he leaves (the tax price rises) or enters (the tax price falls)" (Flatters, Henderson, and Miezkowski (1974), p. 99).1 The prescribed solution is a central authority making transfers from the overpopulated to the underpopulated region. A second type of fiscal extemality is identified in Boadway and Wildasin (1984). This is the case of rent sharing, where the rent associated with a region's fixed factors accrue to individuals on the basis of residency. In this case, the migrant does not account for the effect of his moving on the share of the rent received by others in the region he leaves or enters. Again the prescribed solution is a central authority making transfers. ${ }^{2}$

The importance of determining the validity of the fiscal externality arguments is clear. They have been used to provide an efficiency rationale for the centralized system of interregional transfers employed in Canada (the equalization payments), and could be used to rationalize such a system in any other federation.

1Other papers which deal with the issue of the fiscal externality include Buchanen and Goetz (1972), Stiglitz (1977), Boadway and Flatters (1982) and Wildasin (1980, 1986, 1987). For the related literature which focuses on public good provision see Starrett $(1980,1982)$ and Boadway (1982).

2Rather than explain these fiscal extemalities directly in terms of migration externalities, Broadway and Wildasin explain them in terms of migration distorting regional taxation. 
In a recent paper, Myers (1990) explicitly examined a model of regional tax determination in a fiscal externality environment. It was demonstrated that, while it is true that interregional transfers are necessary for efficiency, it is also true that Nash-competing regional authorities make these efficient transfers; the conclusion being that there is no role for a central authority. The need for transfers arises from the free mobility of a homogeneous population, implying a migration equilibrium characterized by equal utility. For example, with rent sharing, individuals locate to equalize average products. Efficiency, however, requires equalized marginal products. Thus, transfers are required so that average product net of transfers are equalized at the same population distribution as marginal products. In general we require a particular distribution of resources across regions to support the unique efficient allocation compatible with free mobility by competitive behavior. The regional authorities' incentive to make efficient transfers also arises from equal utility. A regional authority maximizing the utility of a representative individual in its own region, but facing the equal utility constraint, has an objective perfectly tied to that of their counterparts in other regions. ${ }^{3}$ Therefore, free mobility provides both the need and the regional incentive for making interregional transfers.

While this result overturns the usual conclusions of the fiscal externality literature, initially it seems fragile. One might suspect that as soon as regional objectives are no longer perfectly tied together by free mobility the result will break down. However, this reasoning ignores important aspects of the result. First, the incentive to make transfers is a general phenomena. The population size of a region affects the region's maximization problem and the interregional transfer is an instrument that allows a region to influence migration and, thus, its population. The Nash equilibrium in Myers was characterized by the marginal benefit of transfers (due to migration) being equal to the marginal cost. That is, regions purchased preferred population distributions. In an environment where the objective functions of regional authorities are not perfectly tied together, a region's incentive to make transfers, while

\footnotetext{
${ }^{3}$ Our focus in this paper will be on the question of transfers and the fiscal externality economy. However, it should be clear that this incentive equivalence between strategically competing authorities has important implications in any environment involving free location choice such as Urban Economics.
} 
weakened, may not disappear. Second, it is not only the incentive but also the need to make transfers that arise from free mobility. Thus, even if the incentive to make transfers is reduced, there may be a directly related reduction in the need for transfers.

This paper examines an extension of the standard fiscal externality economy by assuming that individuals derive non-pecuniary benefit from living in a particular region. Such an extension is of special interest for systems such as the European Economic Community or Canada, which consist of culturally diverse regions. In such systems individuals will have a preference for a particular region for cultural or nationalistic reasons. A second feature of this extension is that, because individuals differ in their degrees of attachment to a particular region and regional authorities are concerned with different subsets of individuals, the objective functions of these authorities will no longer be perfectly tied together.

We assume a population with a continuum of types differing only in their degree of attachment to a particular region. We assume the regions are large and, thus, that their behavior is strategic. We find that the authorities' incentive to make transfers is reduced from the case of no attachment to home. The size of region 1's desired net transfer from 1 to 2 is smaller than that preferred by region 2.4 There is also a range of initial endowments of resources over which no transfers are made by either region in the Nash equilibrium. Further, we find that free location choice does not imply a unique efficient allocation. 5 There is a range of efficient allocations that correspond to a range of distributions of resources. Transfers within this range simply make one region's citizens better off at the expense of the other region's citizens. Finally, we show that the allocations arising from the Nash behavior of regional authorities, even those that involve no interregional transfers, are efficient.

In an environment of free mobility, the traditional arguments favouring a central authority have been based on the efficiency role that such an authority can play in coercing interregional transfers. The primary implication of our result is that there is no efficiency role

\footnotetext{
${ }^{4}$ With no attachment to home, both have the same desired transfer.
}

$5_{\text {By }}$ an efficient allocation we mean an allocation from which it is impossible to make one individual better off without making another worse, given the instruments we allow the authorities. 
for a central authority. To force a region to make transfers can only be justified on the basis of central equity concerns. This holds with or without attachment to home and, thus, without the regional authorities' objectives being perfectly tied together. This rejection of the conclusions of the traditional literature can be traced to their underlying logics. The fiscal externality is an externality, but it is pecuniary, and thus a reflection of efficiently operating markets, not a cause of inefficiency. The logic of the fiscal externality being related to migration distorting regional taxation seems to be based on the assumption that regions would not make transfers and, thus, on a less than complete consideration of the consequences of free location choice on the need and regional incentive for making transfers.

Section 2 describes the model and determines the Nash equilibrium of regional authority behavior. Section 3 describes central authority behavior and proves that the Nash equilibria are efficient. The final section provides conclusions.

\section{THE REGIONAL AUTHORITY}

A nation consists of two regions indexed $i=1,2$. Each region is endowed with a quantity of a fixed factor, $T_{i}$. The national population $(N)$ is assumed sufficiently large to allow a fractional distribution of individuals across regions. $N$ is normalized to unity. Individuals derive utility from consumption of a private good and residence in region 2.6 The preferences for individual $n$ are defined by

$$
V^{n}\left(X^{n}\right)= \begin{cases}U\left(X^{n}\right) & \text { if he lives in region 1 } \\ U\left(X^{n}\right)+n & \text { if he lives in region 2 }\end{cases}
$$

where $X^{n}$ is the consumption of the private good by this individual. $n$ measures the utility the individual derives solely from residence in region 2.7 We assume that $n$ is uniformly distributed over $[0,1]$ and that population is uniformly distributed over $n$. Each individual is below.

6Introducing a public good does not affect our qualitative conclusions. We shall discuss this further

7 Our conclusions do not depend on this additive specification of the utility function. We employ it for simplicity. Similar specification is used by DePalma and Papageorgiou (1988). 
endowed with one unit of labour which he supplies inelastically in his region of residence.

Competitive firms produce the private good with a neo-classical constant returns to scale production function $f_{i}\left(N_{i} ; T_{i}\right)$, where $N_{i}$ is the population of region $i$. They pay labour a wage equal to its marginal product $F_{i}$. The total rent on the fixed factor $\left(R_{i}\right)$ is the residual: $R_{i}=f_{i}-N_{i} F_{i}$

We assume that the regional authorities are endowed with the fixed factor located in their region. 8 We assume that each regional authority has an instrument for making a non-negative interregional transfer to the other region. For region $i$ this is denoted by $S_{i j}$ The authorities raise revenue with a residence based tax, $\Gamma_{i}{ }^{9} \Gamma_{i}$ could be specified as either a head tax or an income tax. For simplicity we utilize the former. Given this structure, the budget constraint for an individual resident in region i is $X_{i}=F_{i}-\Gamma_{i}$. The regional authority i's balanced budget constraint is

$$
S_{i j}=N_{i} \Gamma_{i}+R_{i}+S_{j i}
$$

Using these two equations and the equation for rent to eliminate $\Gamma_{i}$ yields regional feasibility:

$$
f_{i}-N_{i} X_{i}-\left(S_{i j}-S_{j i}\right)=0 .
$$

Individuals maximize utility, are free to choose their region of residence, and take the behaviour of all other agents parametrically. Thus, the migration equilibrium must be characterized by the marginal individual, identified by $n_{l}$, being indifferent between locating in either region, while individuals $n<n_{1}$ locate in region 1 and individuals $n>n_{1}$ locate in 2 , or

$$
\begin{aligned}
& V^{n}{ }^{1}=U\left(X_{1}\right)=U\left(X_{2}\right)+n_{1}, \\
& V^{n}=V^{n_{1}} \quad \forall n<n_{1},
\end{aligned}
$$

${ }^{8}$ As such, our model involves the problem of rent sharing.

${ }^{9}$ By assuming $\Gamma_{i}$ is not indexed by $n$ we have assumed that an authority can not discriminate against a particular individual on the basis of their non-pecuniary attachment to a particular region. This shall be discussed below. Thus, this model is not applicable to regions where this type of non-pecuniary tax discrimination is allowed. 
and $V^{n}>V^{n} \quad \forall n>n_{1}$.

Given our distribution of population over $[0,1]$, it follows that

$$
N_{1}=\int_{0}^{n_{1}} d n=n_{1} \text { and } N_{2}=\int_{n_{1}}^{1} d n=1-n_{1},
$$

Thus, $n_{1}$ not only denotes the marginal individual but it is also the size of the population in region 1. Substitution of (1) and (3) into (2) determines $N_{i}$ as an implicit function of $\left(S_{12}\right.$, $\left.S_{21}\right)$.

The regional authority $i$ will be assumed to choose $S_{i j}$ so as to maximize the sum of utilities of a subset of the national population, subject to (1), (2) and (3), and making the Nash conjecture that $S_{j i}$ is given. ${ }^{10}$ The second constraint states that the regional authority's problem is characterized by private free location choice. Since the regional authority cannot impose migration restrictions, it cannot choose $N_{i}$ directly and, therefore, faces the constraint of equalized utility at the margin. The first and third constraints impose regional self-sufficiency, and national population respectively. Thus, regional authority l's problem is,

$$
\max _{S_{12}} W_{1}=\int_{0}^{n^{*}} V^{n} d n, \quad \text { s.t. (1), (2), (3) and } S_{12} \geq 0 \text {. }
$$

Alternatively, their problem is

$$
\max _{S_{12}} W_{1}=\int_{0}^{n} U\left(X_{1}\right) d n+\int_{n_{1}}^{n^{*}}\left[U\left(X_{2}\right)+n\right] d n, \quad \text { s.t. (2) and } S_{12} \geq 0,
$$

where from (1) and (3)

$$
X_{1}=\frac{f_{1}-s_{12}+s_{21}}{n_{1}}
$$

and

$$
X_{2}=\frac{f_{2}+S_{12}-S_{21}}{I-n_{1}}
$$

10This specification is quite general. It allows, for example, regional authority 2 to care only about the individual most attached to his region or alternatively the whole national population. With a variable population pool the specification of $\mathrm{n}^{*}$ as a parameter is important, as otherwise the authority would care directly about their population size. For example, they would trade off utility for increased population size. 
The Kuhn-Tucker conditions for this problem are

$$
\frac{d W_{1}}{d S_{12}} \leq 0, S_{12} \geq 0, \text { and } \frac{d W_{1}}{d S_{12}} s_{12}=0
$$

where

$$
\frac{d W_{1}}{d S_{12}}=n_{1} U^{\prime}\left(X_{1}\right) \frac{d X_{1}}{d S_{12}}+\left(n^{*}-n_{1}\right) U^{\prime}\left(X_{2}\right) \frac{d X_{2}}{d S_{12}}
$$

where from (4) and (5),

$$
\begin{aligned}
& \frac{d X_{1}}{d S_{12}}=\frac{\left(F_{1}-X_{1}\right)}{n_{1}} \frac{d n_{1}}{d S_{12}}-\frac{1}{n_{1}}, \\
& \frac{d X_{2}}{d S_{12}}=\frac{1}{1-n_{1}}-\frac{\left(F_{2}-X_{2}\right)}{1-n_{1}} \frac{d n_{1}}{d S_{12}},
\end{aligned}
$$

and $\frac{d n_{1}}{d S_{12}}$ is the perceived migration response due to the transfer. ${ }^{11}$ To obtain $\frac{d n_{1}}{d S_{12}}$ totally differentiate the national population constraint $\left(N_{2}=1-n_{1}\right)$ and the migration equilibrium condition (2), respectively, to get:

$$
\left[\begin{array}{cc}
1 & 1 \\
U^{\prime}\left(X_{1}\right) \frac{\left(F_{1}-X_{1}\right)}{n_{1}}-1 & -U^{\prime}\left(X_{2}\right) \frac{\left(F_{2}-X_{2}\right)}{I-n_{1}}
\end{array}\right]\left[\begin{array}{l}
d n_{1} \\
d N_{2}
\end{array}\right]=\left[\begin{array}{c}
0 \\
\frac{U^{\prime}\left(X_{1}\right)}{n_{1}}+\frac{U^{\prime}\left(X_{2}\right)}{I-n_{1}}
\end{array}\right] d S_{12} .
$$

Using Cramer's rule

$$
\frac{d n_{1}}{d S_{12}}=\frac{-\left[U^{\prime}\left(X_{1}\right) / n_{1}+U^{\prime}\left(X_{2}\right) /\left(1-n_{1}\right)\right]}{|A|},
$$

where $|A|=1-U^{\prime}\left(X_{2}\right) \frac{\left(F_{2}-X_{2}\right)}{1-n_{1}}-U^{\prime}\left(X_{1}\right) \frac{\left(F_{1}-X_{1}\right)}{n_{1}}$ is the Jacobian of the system, which should be positive for the stability of the migration equilibrium.

11The migration response is perceived rather than actual to achieve consistency with the authority's conjecture that $S_{21}$ is fixed. 
Substituting (7), (8) and (9) into (6), the reader can readily verify that the Kuhn-Tucker conditions for region 1's problem are

$$
\begin{aligned}
& \left(F_{2}-X_{2}\right)-\left(F_{1}-X_{1}\right)-\frac{1-n_{1}}{U^{\prime}\left(X_{2}\right)}+\Psi \leq 0, s_{12} \geq 0, \\
& \text { and }\left[\left(F_{2}-X_{2}\right)-\left(F_{1}-X_{1}\right)-\frac{1-n_{1}}{U^{\prime}\left(X_{2}\right)}+\Psi\right] s_{12}=0,
\end{aligned}
$$

where

$$
\Psi=\left\{\begin{array}{l}
{\left[\frac{n^{*}-n_{1}}{n^{*}}\right]\left[\frac{1-n_{1}}{U^{\prime}\left(X_{2}\right)}+\frac{n_{1}}{U^{\prime}\left(X_{1}\right)}\right]>0 \text { for } n^{*}>n_{1},} \\
0 \text { for } n^{*} \leq n_{1} .
\end{array}\right.
$$

Interpretation of the authority's behavior is straightforward. First, consider the case where $n^{*} \leq n_{1}$, so that in equilibrium all the agents region 1 cares for end up in region 1 . Substituting (7) into (6) and rearranging we derive a marginal principle:

$$
\left(F_{1}-X_{1}\right) \frac{d n_{1}}{d S_{12}} \leq 1
$$

Now, $\frac{d n_{1}}{d S_{12}}$ is the migration induced by one more unit of transfer, while $F_{1}-X_{1}$ is the net benefit to region 1 of having another individual. Therefore, the left hand side of (12) is the marginal benefit of the transfer, while the right hand side is the marginal cost. Thus, according to (12) region 1 will make transfers as long as the marginal benefit of doing so is greater than the marginal cost.

Now consider the case where in equilibrium the authority cares for some individuals residing in region 2 (that is, $n^{*}>n_{1}$ )..$^{12}$ By substituting (7), (8) and (9) into (6) we derive the general condition (10), and utilizing (11), the unambiguous conclusion that the authority will have a stronger incentive to make transfers.

12If one adds the condition that $n^{*}=n_{1}$ in an equilibrium then the new equilibirum condition is (10) with $\Psi=0$. This follows from (10) being necessary for any $n^{*}$ and thus for $n_{1}=n^{*}$. Further, with (10) satisfied but $n^{*}>n_{1}$, we cannot have equilibrium. Thus the necessary condition is (10) with $n^{*}=n_{1}$, or $\Psi=0$. 
Finally, when there is no attachment to home and the authority has $n^{*} \leq n_{1}$ then it is easily verified that (10) reduces to $\left(F_{2}-X_{2}\right)-\left(F_{1}-X_{1}\right) \leq 0$. Thus, authority 1 has less incentive to make a transfer than he would without attachment to region 2 .

The problem of authority 2 is very similar to that for authority 1 . They choose $S_{21}$ to maximize the sum of the utilities of agents $n^{* *}$ to 1 . Their problem, therefore, is

$$
\begin{aligned}
\max _{21} W_{2} & =\int_{n^{* *}}^{1} V^{n} d n \\
& =\int_{n^{* *}}^{n_{1}} U\left(X_{1}\right) d n+\int_{n_{1}}^{1}\left[U\left(X_{2}\right)+n\right] d n,
\end{aligned}
$$

s.t. (1), (2), (3), and $S_{21} \geq 0$.

Using the same method as above, we can easily show that the Kuhn-Tucker conditions for this problem are:

$$
\begin{aligned}
& \left(F_{1}-X_{1}\right)-\left(F_{2}-X_{2}\right)-\frac{n_{1}}{U^{\prime}\left(X_{1}\right)}+\Omega \leq 0, \quad S_{21} \geq 0, \\
& \text { and }\left[\left(F_{1}-X_{1}\right)-\left(F_{2}-X_{2}\right)-\frac{n_{1}}{U^{\prime}\left(X_{1}\right)}+\Omega\right] S_{21}=0,
\end{aligned}
$$

where

$$
\Omega=\left\{\begin{array}{l}
\frac{n_{1}-n^{* *}}{I-n^{* *}}\left[\frac{n_{1}}{U^{\prime}\left(X_{1}\right)}+\frac{1-n_{1}}{U^{\prime}\left(X_{2}\right)}\right]>0 \text { for } n^{* *}<n_{1} . \\
0 \text { for } n^{* *} \geq n_{1} .
\end{array}\right.
$$

(13) has the same interpretation that (10) had for region 1. It is a rearrangement of the marginal principle that says region 2 should make transfers as long as the marginal benefit of doing so is greater than the marginal cost. Note that when there is no attachment to home and $n^{* *} \geq n_{1}$, then (13) reduces to $\left(F_{1}-X_{1}\right)-\left(F_{2}-X_{2}\right) \leq 0$. Thus, attachment also weakens region 2's incentive to make transfers.

Combining (10) and (13), we can see that in a Nash equilibrium we have

$$
\frac{-\left(1-n_{1}\right)}{U^{\prime}\left(X_{2}\right)}+\Psi \leq\left(F_{1}-X_{1}\right)-\left(F_{2}-X_{2}\right) \leq \frac{n_{1}}{U^{\prime}\left(X_{1}\right)}-\Omega \text {. }
$$


With $n^{* *} \geq n_{1}, n^{*} \leq n_{l}$, and no attachment to home the Nash equilibrium is characterized by $F_{1}-X_{1}=F_{2}-X_{2}$, which with equal utility reduces to $F_{1}=F_{2}$. Thus, with no attachment to home the equilibrium involves the authorities making efficient transfers such that national product is maximized. As noted above, attachment to home reduces both authorities' incentive to make transfers, thus, (15) involves a range of allocations: this range corresponds to the set of initial distributions of resources which induce neither region to make a transfer. ${ }^{13}$

The reason for this disagreement over the size of the transfer with attachment to home is straightforward. With no attachment to home, when region 2 maximizes $U\left(X_{2}\right)$ subject to $U\left(X_{1}\right)=U\left(X_{2}\right)$ it is in effect maximizing $U\left(X_{1}\right)$ : because of the free mobility constraint there is no disagreement. With attachment to home, however, when region 2 maximizes the utility of an inframarginal agent, say $n=1$, it is maximizing $U\left(X_{2}\right)+1$ subject to equalized utility at the margin $\left(U\left(X_{1}\right)=U\left(X_{2}\right)+n_{1}\right)$, which means that it is in effect maximizing $U\left(X_{1}\right)-n_{1}+1$. But when region 1 maximizes the utility of an inframarginal agent, say $n=0$, it is maximizing $U\left(X_{1}\right)$. Thus the authorities, maximizing the utility of inframarginal individuals in their region, disagree over $n_{1}$; region 2 prefers a smaller $n_{1}$ than does region 1 . Thus, region 1's desired $S_{12}$ is smaller than region 2's desired $S_{12}$.

If an authority cares about non-residents $\left(n^{*}>n_{1}\right.$ or $\left.n^{* *}<n_{1}\right)$ then the range over which no transfers are made shrinks. When $n^{*}=1$ and $n^{* *}=0$, so that both regions have the same objective function, involving the sum of utilities of all agents, then

$$
\frac{-\left(I-n_{1}\right)}{U^{\prime}\left(X_{2}\right)}+\Psi=\frac{n_{1}}{U^{\prime}\left(X_{1}\right)}-\Omega=n_{1}\left(1-n_{1}\right)\left[\frac{1}{U^{\prime}\left(X_{1}\right)}-\frac{1}{U^{\prime}\left(X_{2}\right)}\right]
$$

and thus

$$
\left(F_{1}-X_{1}\right)-\left(F_{2}-X_{2}\right)=n_{1}\left(1-n_{1}\right)\left[\frac{1}{U^{\prime}\left(X_{1}\right)}-\frac{1}{U^{\prime}\left(X_{2}\right)}\right] .
$$

Therefore only when both authorities care about the whole national population equally does

\footnotetext{
13Using the regional authorities' budget constraints for the case of no transfers, we dcrive $F_{i}-X_{i}=-R_{i} / n_{i}$. This range then involves a relatively equal per person value of the initial distribution of resources.
} 
the range over which no transfers are made collapse to a point. This confirms the intuition of those who believed that as one moves away from the authorities' objectives being perfectly tied together by the free mobility of a homogeneous population the incentive to make transfers would be reduced. Also note that even in the extreme case where $n^{*}=1$ and $n^{* *}=0$ we do not have both regions trying to make positive transfers.

\section{THE CENTRAL AUTHORITY}

In this section we show that all Nash equilibria, including those that involve no interregional transfers, are efficient. By an efficient allocation we mean an allocation from which it is impossible to make one person better off without making another worse off, given the environment of free location choice and equal consumption within each region by agents with the same abilities but different non-pecuniary attachment to a particular region.

To begin we first specify the relationship between the levels of utility for all agents in the economy such that they are consistent with all individuals in a region receiving the same consumption and with equal utility at the margin. We choose a real valued function $\bar{V}:[0,1] \rightarrow R$, which assigns to each individual $n \in[0,1]$ a level of utility $\bar{V}^{n}$ such that for a given real number $\bar{U}$ and for a given $n_{1}$

$$
\bar{V}^{n}=\left\{\begin{array}{l}
\bar{U} \quad \text { for } n \leq n_{1} \\
\bar{U}-n_{1}+n \quad \text { for } n \geq n_{1}
\end{array}\right.
$$

We then require the utility profile of the agents in the economy to coincide with this real valued function; that is, we require

$$
V^{n}=\bar{V}^{n} \quad \forall n
$$

or, alternatively,

$$
U\left(X^{n}\right)=\bar{U} \quad \forall n \leq n_{1}
$$

and

$$
U\left(X^{n}\right)=\bar{U}-n_{1} \quad \forall n \geq n_{1}
$$


Note that (17) requires everyone in region 1 to have the same level of consumption, $X_{l}$, such that $U\left(X_{1}\right)=\bar{U}$. Similarly, (18) requires everyone in region 2 to have the same level of consumption, $X_{2}$, such that $U\left(X_{2}\right)=\bar{U}-n_{1}$. (17) and (18) then give us a relationship between $X_{1}, X_{2}$ and $n_{1}:$

$$
U\left(X_{1}\right)=U\left(X_{2}\right)+n_{1},
$$

which is the equal utility constraint of the previous section. ${ }^{14}$ The national feasibility constraint is 15

$$
f_{1}+f_{2}=n_{1} X_{1}+\left(l-n_{1}\right) X_{2} .
$$

In (19) and (20) we have two equations in three unknowns: $n_{1}, X_{1}$, and $X_{2}$. Thus for a given $n_{1},(19)$ and (20) determine $X_{1}$ and $X_{2}$. By considering all $n_{1} \in[0,1]$ we identify all allocations which are feasible and consistent with $\bar{V}^{n}$. To identify the subset of these allocations which are efficient we must find those allocations at which a change in $n_{1}$ leads to at least one individual being worse off. If $\frac{d X_{1}}{d n_{1}}$ and $\frac{d X_{2}}{d n_{1}}$ are of opposite sign at least one individual (for example either individual $n=0$ or $n=1$ ) is made worse off by a change in $n_{1} \cdot 16$

Totally differentiating (19) and (20) with $X_{1}$ and $X_{2}$ endogenously determined yields:

$$
\left[\begin{array}{cr}
U^{\prime}\left(X_{1}\right) & -U^{\prime}\left(X_{2}\right) \\
n_{1} & \left(1-n_{1}\right)
\end{array}\right]\left[\begin{array}{l}
d X_{1} \\
d X_{2}
\end{array}\right]=\left[\begin{array}{c}
1 \\
\left(F_{1}-X_{1}\right)-\left(F_{2}-X_{2}\right)
\end{array}\right] d n_{1} .
$$

14With a continuum of identical individuals, rather than a continuum of types, the standard approach for identifying the subset of Pareto optimal allocations consistent with equal treatment of equals within a region and with free location choice is found in Wildasin (1987). The analogous real valued function would be $\bar{V}^{n}=\bar{U} \forall n$. The function is based on a Rawlsian social welfare function.

15 By writing the national feasibility constraint in this way we make the choice of interregional transfers implicit in the choice of $\mathbf{n}_{1}$.

${ }^{16}$ This approach when applied to the standard fiscal externality environment of local public goods and no attachment, with $\bar{V}^{n}=\bar{U} \forall n$ yields the standard first order conditions: The Samuelson condition and $\left(F_{1}-X_{1}\right)-\left(F_{2}-X_{2}\right)=0$. With no public goods and no attachment it yields $F_{1}-F_{2}=0$. These results are shown in the Appendix. 
Then using Cramer's rule yields:

$$
\begin{aligned}
& \frac{d X_{1}}{d n_{1}}=\frac{\left(1-n_{1}\right)+U^{\prime}\left(X_{2}\right)\left[\left(F_{1}-X_{1}\right)-\left(F_{2}-X_{2}\right)\right]}{n_{1} U^{\prime}\left(X_{2}\right)+\left(I-n_{1}\right) U^{\prime}\left(X_{1}\right)} \\
& \frac{d X_{2}}{d n_{1}}=\frac{-n_{1}+U^{\prime}\left(X_{1}\right)\left[\left(F_{1}-X_{1}\right)-\left(F_{2}-X_{2}\right)\right]}{n_{1} U^{\prime}\left(X_{2}\right)+\left(I-n_{1}\right) U^{\prime}\left(X_{1}\right)}
\end{aligned}
$$

Therefore,

$$
\frac{d X_{1}}{d n_{1}} \geq 0 \text { as }\left(F_{1}-X_{1}\right)-\left(F_{2}-X_{2}\right) \gtreqless-\frac{\left(1-n_{1}\right)}{U^{\prime}\left(X_{2}\right)}
$$

and

$$
\frac{d X_{2}}{d n_{1}} \geq 0 \text { as }\left(F_{1}-X_{1}\right)-\left(F_{2}-X_{2}\right) \geq \frac{n_{1}}{<} \frac{U^{\prime}\left(X_{1}\right)}{} \text {. }
$$

Thus, the subset of efficient allocations at which $\frac{d X_{1}}{d n_{1}}$ and $\frac{d X_{2}}{d n_{1}}$ are of opposite sign satisfy:

$$
\frac{-\left(1-n_{1}\right)}{U^{\prime}\left(X_{2}\right)} \leq\left(F_{1}-X_{1}\right)-\left(F_{2}-X_{2}\right) \leq \frac{n_{1}}{U^{\prime}\left(X_{1}\right)} .
$$

Comparison of (15) and (25) reveals that the allocations resulting from the Nash behaviour of the competing regions are in fact efficient, because $\Psi$ and $\Omega$ are non-negative, and so if (15) is satisfied then (25) must also be satisfied.

The primary implication of this result is that there is no efficiency role for a central authority with or without attachment to home, and thus, without the regional authorities objectives being tied together. The regional authorities make the efficient transfers in purchasing a preferred population distribution. The intuition for why there is a range of efficient allocations is simply that what is best for those residing in region 1 is not what's best for those residing in region 2. To force a larger transfer from 1 to 2 than desired by region 1 is to make agents in region 2 better off but only at the expense of agents in region 1 . Thus, if the regions do not make transfers to force them to do so can only be justified on the basis of central equity concerns. 
The result that the Nash is efficient might be considered surprising for two reasons; the strategic interaction and the logic of the fiscal externality. A Nash equilibrium is usually inefficient because each player makes the wrong conjecture in assuming that there is no reaction by his opponent to changes in his strategic variable. Now, in our model the Kuhn-Tucker conditions (10) and (13) imply that when region 1 is in an interior solution, so that $S_{12}>0$, then $S_{21}=0$ independently of the size of $S_{12}$. Similarly, when $S_{21}$ is positive, then $S_{12}=0$ independently of the size of $S_{21}$. Thus, even though in our model each region makes the Nash conjecture, this conjecture is correct. Therefore, in our model the equilibrium is efficient for the same reason that in a standard duopoly model the equilibrium is efficient when each firm has consistent conjectures about his opponent.

Thus, our result should only surprise those that have not rejected the logics of the fiscal externality - that migration involves an externality which generally leads to inefficient outcomes, or that regional taxation will distort the migration decision. Our model involves a type of fiscal externality discussed in for example Boadway and Wildasin (1984), that associated with rent sharing. To retum to the original environment of the fiscal extemality we need to introduce local public goods into our model. We have done so and found that this addition does not alter our conclusion that the Nash equilibrium is efficient. 17 Thus, our results do not lend support to the conclusions of the fiscal externality literature. The rejection of the conclusions of the traditional literature can be traced to their underlying logics. The fiscal externality as exposited by Flatters et al. is an externality, but it is pecuniary, and thus a reflection of efficiently operating markets, not a cause of inefficiency. The logic of the fiscal externality being related to migration distorting regional taxation seems to be based on the

\footnotetext{
${ }^{17}$ These results are shown in the appendix. We must qualify this in one way. Without public goods our result does not depend on our specification of the utility function. With public goods if $n$ enters the utility function in such a way that it affects the marginal rate of substitution between the public and private goods then to achieve Samuelson public good provision requires a regional authority with the power to discriminate between individuals on the basis of $n$ - that is tax discrimination on the basis of an individual's non-pecuniary attachment to home. This type of problem is one of a lack of instruments and is not connected to the logic of the fiscal externality. We shall discuss the consequence of allowing authorities to discriminate on the basis of $n$ below.
} 
assumption that regions will not make transfers and thus on a less than complete consideration of the consequences of free location choice on the need and regional incentive for making transfers.

Finally, there is one important qualification of our results. The model is built on the assumption that authorities cannot discriminate in their taxation on the basis of non-pecuniary attachment to home. We made this assumption to capture the fact that such discrimination is not allowed in any federation of which we are aware. Secondly, allowing for the possibility of expropriative taxation of a particular individual is not equivalent to allowing authorities to make migration restrictions, but it is moving strongly in this direction and thus away from mobility and thus such issues as the fiscal externality. However, if we did allow for this sort of discrimination our results would change. Both the behavior of regional authorities and the characterization of an efficient allocation would change. Thus, our model is not appropriate for economies where such discrimination is allowed. Extension to that environment, which would involve a kind of tax competition for bodies, is left for the future.

\section{CONCLUSION}

This paper has considered an economy in which individuals have different degrees of attachment to home in a regional model otherwise consistent with the fiscal externality environment. This extension has two advantages. It allows for some applicability to culturally diverse systems of regions such as the European Economic Community and Canada, and unlike the standard fiscal externality setting, involves disagreement among regional authorities about the allocation of resources across regions.

We find that a regional authority may have an incentive to make interregional transfers in purchasing a preferred population. With no attachment to home the authorities agree on the size of the transfer, both desiring the transfer which maximizes national product. With attachment to home the incentive to make transfers by both regions is reduced. There is a range of relatively equal initial endowments over which the authorities will not make transfers. 
However, we also find that all Nash equilibria are efficient. Because agents differ in their degrees of attachment to a region, there is a range of efficient allocations. This range corresponds to the set of initial endowments of resources over which the regional authorities will not make transfers. Centrally coerced transfers within this range make one region's citizens better off but only at the expense of the other region's citizens and thus can only be justified on the basis of central equity concerns. Our model is consistent with the fiscal externality economy, yet we find no inefficiency associated with migration or decentralized regional taxation. Thus, our results do not lend support to the conclusions or logic of the fiscal externality literature. 


\section{Appendix}

Proof of the results with public goods and generalized utility functions

Let $Z_{i}$ be the provision of the pure public good in region $i$. We assume that the technology for producing public goods is such that one unit of the private good can be turned into one unit of the public good.

The utility function of agent $n$ is

$$
V^{n}= \begin{cases}U\left(X^{n}, Z_{1}\right) & \text { if he lives in region } 1 \\ g\left(U\left(X^{n}, Z_{2}\right), n\right) & \text { if he lives in region 2, }\end{cases}
$$

where $g\left(U\left(X^{n}, Z_{2}\right), n\right)$ is a continuous function that is strictly monotonic in both its arguments. Thus, the utility function of the agent if he lives in region 2 is a monotonic transformation of his utility function if he lives in region 1. Also agents with higher $n$ have greater degrees of attachment to region 2 .

First, consider the central authority's problem. The real valued function $\bar{V}:[0,1] \rightarrow R$ assigning to each individual $n \in[0,1]$ a level of utility $\bar{V}^{n}$ is such that for given $\bar{U}_{1}, \bar{U}_{2}$ and $n_{1}$ :

$$
\bar{V}^{n}= \begin{cases}\bar{U}_{1} & \forall n \leq n_{1} \\ g\left(\bar{U}_{2}, n\right) & \forall n \geq n_{1}\end{cases}
$$

with $\bar{U}_{1}=g\left(\bar{U}_{2}, n_{1}\right)$.

We require the utility profile of the agents in the economy to coincide with $\bar{V} \longrightarrow$ that is, we require

$$
V^{n}=\bar{V}^{n} \quad \forall n .
$$


This requires everyone in region 1 to consume the same level of the private good, $X_{1}$, such that $U\left(X_{1}, Z_{1}\right)=\bar{U}_{1}$. It also requires everyone in region 2 to consume the same level of the private good, $X_{2}$, such that $U\left(X_{2}, Z_{2}\right)=\bar{U}_{2}$. (I) then gives us the following relationship:

$$
U\left(X_{1}, Z_{1}\right)=g\left(U\left(X_{2}, Z_{2}\right), n_{1}\right)
$$

For simplicity, henceforth we shall denote $g\left(U\left(X_{2}, Z_{2}\right), n\right)$ by $g^{n}$. We shall also use $g_{i}^{n}$ to denote the derivative of $g^{n}$ with respect to variable $i$. Hence, for example,

$$
g_{X}^{n}=\frac{\partial g^{n}}{\partial U\left(X_{2}, Z_{2}\right)} U_{X}\left(X_{2}, Z_{2}\right)
$$

Now recall that in the main text of the paper, equations (19) and (20) gave two relationships between $X_{1}, X_{2}$ and $n_{1}$ that were consistent with $\bar{V}^{n}$ and with feasibility. To find the subset of these allocations that were efficient, we then chose $n_{1}$ such that $\frac{d X_{1}}{d n_{1}}$ and $\frac{d X_{2}}{d n_{1}}$ were of opposite sign. This meant that it was impossible to change $n_{1}$ in order to raise $U\left(X_{1}\right)$ without reducing $U\left(X_{2}\right)$, and vice versa. That procedure was in fact maximizing $\delta U\left(X_{1}\right)+$ (1- $\delta) U\left(X_{2}\right)$ for $\delta \in[0,1]$ subject to (19) and (20). Similarly, here we can find the set of efficient allocations that we are interested in by maximizing

$$
\delta U\left(X_{1}, Z_{1}\right)+(1-\delta) U\left(X_{2}, Z_{2}\right) \quad \forall \delta \in[0,1]
$$

subject to (II) and national feasibility:

$$
f_{1}+f_{2}=n_{1} X_{1}+\left(1-n_{1}\right) X_{2}+Z_{1}+Z_{2} \text {. }
$$

The Lagrangian for this problem is

$$
\begin{aligned}
\mathscr{L}=\delta U\left(X_{1}, Z_{1}\right)+(1-\delta) U\left(X_{2}, Z_{2}\right) & +\lambda\left[U\left(X_{1}, Z_{1}\right)-g^{n}\right] \\
& +\mu\left[f_{1}+f_{2}-n_{1} X_{1}-\left(1-n_{1}\right) X_{2}-Z_{1}-Z_{2}\right] .
\end{aligned}
$$

The first-order conditions are

$$
\begin{aligned}
& \frac{\partial \mathscr{L}}{\partial X_{1}}=\delta U_{X}\left(X_{1}, Z_{1}\right)+\lambda U_{X}\left(X_{1}, Z_{1}\right)-\mu n_{1}=0 \\
& \frac{\partial \mathscr{L}}{\partial X_{2}}=(1-\delta) U_{X}\left(X_{2}, Z_{2}\right)-\lambda g_{X}^{{ }^{1}}-\left(1-n_{1}\right) \mu=0
\end{aligned}
$$




$$
\begin{aligned}
& \frac{\partial \mathscr{L}}{\partial Z_{1}}=\delta U_{Z}\left(X_{1}, Z_{1}\right)+\lambda U_{Z}\left(X_{1}, Z_{1}\right)-\mu=0 \\
& \frac{\partial \mathscr{L}}{\partial Z_{2}}=(I-\delta) U_{Z}\left(X_{2}, Z_{2}\right)+\lambda g_{Z}^{n_{1}}-\mu=0 \\
& \frac{\partial \mathscr{L}}{\partial n_{1}}=-\lambda g_{n}^{{ }^{1}}+\mu\left(F_{1}-X_{1}-F_{2}+X_{2}\right)=0
\end{aligned}
$$

Solving (III) for $\mu$, we get

$$
\mu=\frac{(\delta+\lambda) U_{X}\left(X_{1}, Z_{1}\right)}{n_{1}}
$$

Substituting for $\mu$ from (VIII) into (IV), we get the Samuelson condition for region 1:

$$
\frac{n_{1} U_{Z}\left(X_{1}, Z_{1}\right)}{U_{X}\left(X_{1}, Z_{1}\right)}=1
$$

Similarly, (IV) and (VI) give us the Samuelson condition for region 2.

Now substitute for $\mu$ from (VIII) into (IV), and solving for $\lambda$, we get

$$
\lambda=\frac{(1-\delta) U_{X}\left(X_{2}, Z_{2}\right)-\frac{1-n_{1}}{n_{1}} \delta U_{X}\left(X_{1} Z_{1}\right)}{g_{X}^{n_{1}}+\frac{1-n_{1}}{n_{1}} U_{X}\left(X_{1}, Z_{1}\right)}
$$


(VIII) and $(\mathrm{X})$ now give us:

$$
\frac{\mu}{\lambda}=\frac{U_{X}\left(X_{1}, Z_{1}\right)}{n_{1}}+\frac{g_{X}^{n_{1}}+\frac{1-n_{1}}{n_{1}} U_{X}\left(X_{1}, Z_{1}\right)}{(1-\delta) U_{X}\left(X_{2}, Z_{2}\right)-\frac{I-n_{1}}{n_{1}} \delta U_{X}\left(X_{1}, Z_{1}\right)} \frac{\delta U_{X}\left(X_{1}, Z_{1}\right)}{n_{1}}
$$

As $\delta \in[0,1],(\mathrm{VII})$ and $(\mathrm{XI})$ imply that

$$
-g_{n}^{n} \frac{1-n_{1}}{g_{X}^{n} 1} \leq\left(F_{1}-X_{1}\right)-\left(F_{2}-X_{2}\right) \leq \frac{g_{n}^{n_{1}} n_{1}}{U_{X}\left(X_{1}, Z_{1}\right)}
$$

For the specification in the main text where $g_{n}^{n_{1}}=1, g_{X}^{n_{1}}=U^{\prime}\left(X_{2}\right)$, and $U_{X}\left(X_{1}, Z_{1}\right)=U^{\prime}\left(X_{1}\right)$, (XII) simplifies to (25).

In the standard fiscal externality environment $g\left(U\left(X_{2}, Z_{2}\right), n\right)=U\left(X_{2}, Z_{2}\right)$ for all $n$. Thus $g_{n}^{n}=0$ for all $n$. This means that (XII) in that case is

$$
\left(F_{1}-X_{1}\right)-\left(F_{2}-X_{2}\right)=0 \text {. }
$$

The Samuelson conditions will still hold. This proves the assertion in footnote 16 .

Now consider the allocations that result from the Nash behaviours of the competing regions. For simplicity we consider the case where each authority cares about the immobile agent in its region. We show that the Samuelson conditions are met in both regions and that (XII) is satisfied. Extensions to cases in which authorities care about some of the agents who end up living outside their regions is straightforward; and as in the text of the paper such an extension simply shrinks the range of values for $\left(F_{1}-X_{1}\right)-\left(F_{2}-X_{2}\right)$.

Region 1's problem is:

$$
\begin{aligned}
& \max _{12}, Z_{1}=U\left(X_{1}, Z_{1}\right), \\
& \text { where } X_{1}=\frac{f_{1}-s_{12}+s_{21}-Z_{1}}{n_{1}}
\end{aligned}
$$


The optimality conditions are:

$$
\begin{aligned}
& \frac{d W_{1}}{d Z_{1}}=\frac{-U_{X}\left(X_{1}, Z_{1}\right)}{n_{1}}+U_{Z}\left(X_{1}, Z_{1}\right)+U_{X}\left(X_{1}, Z_{1}\right) \frac{F_{1}-X_{1}}{n_{1}} \frac{\partial n_{1}}{\partial Z_{1}}=0, \\
& \frac{d W_{1}}{d S_{12}}=U_{X}\left(X_{1}, Z_{1}\right)\left[\frac{-1}{n_{1}}+\frac{F_{1}-X_{1}}{n_{1}} \frac{\partial n_{1}}{\partial S_{12}}\right] \leq 0, S_{12} \leq 0, S_{12} \frac{\partial W_{1}}{\partial Z_{12}}=0 .
\end{aligned}
$$

To obtain $\frac{\partial n_{1}}{\partial Z_{1}}$ and $\frac{\partial n_{1}}{\partial S_{12}}$ differentiate totally the national population constraint $\left(n_{1}+N_{2}=1\right)$ and the migration constraint $\left(U\left(X_{1}, Z_{1}\right)=g^{n}{ }^{1}\right)$ to get

$$
\begin{aligned}
& {\left[\begin{array}{cc}
1 & 1 \\
U_{X}\left(X_{1}, Z_{1}\right) \frac{F_{1}-X_{1}}{n_{1}}-g_{n} n_{1} & -g_{X}^{n_{1}} \frac{F_{2}-X_{2}}{I-n_{1}}
\end{array}\right]\left[\begin{array}{l}
d n_{1} \\
d N_{2}
\end{array}\right]} \\
& =\left[\begin{array}{c}
0 \\
-U_{Z}\left(X_{1}, Z_{1}\right)+\frac{U_{X}\left(X_{1}, Z_{1}\right)}{n_{1}}
\end{array}\right] d Z_{1}+\left[\begin{array}{c}
0 \\
\frac{U_{X}\left(X_{1}, Z_{1}\right)}{n_{1}}+\frac{g_{X}^{n_{1}}}{I-n_{1}}
\end{array}\right] d S_{12}
\end{aligned}
$$

The Jacobian of this system is

$$
|J|=g_{n}^{n_{1}}-g_{X}^{n_{1}} \frac{F_{2}-X_{2}}{I-n_{1}}-U_{X}\left(X_{1}, Z_{1}\right) \frac{F_{1}-X_{1}}{n_{1}}
$$

which has to be positive for stability.

Using Cramer's rule, we get:

$$
\frac{\partial n_{1}}{\partial Z_{1}}=\frac{1}{\Gamma}\left[U_{Z}\left(X_{1}, Z_{1}\right)-\frac{U_{X}\left(X_{1}, Z_{1}\right)}{n_{1}}\right]
$$


and

$$
\frac{\partial n_{1}}{\partial S_{12}}=\frac{-1}{\Gamma}\left[\frac{U_{X}\left(X_{1}, Z_{1}\right)}{n_{1}}+\frac{g_{X}^{n_{1}}}{1-n_{1}}\right]
$$

Substituting for $\frac{\partial n_{1}}{\partial S_{12}}$ from $(X V I)$ into (XIV) we get the condition:

$$
-|J|-\left(F_{1}-X_{1}\right)\left[\frac{U_{X}\left(X_{1}, Z_{1}\right)}{n_{1}}+\frac{g_{X}^{n_{1}}}{1-n_{1}}\right] \leq 0
$$

which upon substituting for $|J|$ reduces to

$$
\frac{-g_{n}^{n}\left(1-n_{1}\right)}{g_{X}^{n} 1} \leq\left(F_{1}-X_{1}\right)-\left(F_{2}-X_{2}\right) \text {. }
$$

Now substituting for $\frac{\partial n_{1}}{\partial Z_{1}}$ into (XIII) we get:

$$
\left[U_{Z}\left(X_{1}, Z_{1}\right)-\frac{U_{X}\left(X_{1}, Z_{1}\right)}{n_{1}}\right]\left[|J|+U_{X}\left(X_{1}, Z_{1}\right) \frac{F_{1}-X_{1}}{n_{1}}\right]=0
$$

The term $|J|+U_{X}\left(X_{1}, Z_{1}\right) \frac{F_{1}-X_{1}}{n_{1}} \neq 0$. Therefore, (XIX) gives us the Samuelson condition for region 1 :

$$
\frac{n_{1} U_{Z}\left(X_{1}, Z_{1}\right)}{U_{X}\left(X_{1}, Z_{1}\right)}=1
$$

Now consider region 2's problem:

$$
\max _{21, Z_{2}} W_{2}=g\left(U\left(X_{2}, Z_{2}\right), 1\right)
$$

where $\mathrm{X}_{2}=\frac{f_{2}+S_{12}-S_{21}-Z_{2}}{I-n_{1}}$ 
The first-order conditions are:

$$
\begin{aligned}
& \frac{\partial W_{2}}{\partial Z_{2}}=g_{Z}^{1}-\frac{g_{X}^{1}}{I-n_{1}}+\frac{F_{2}-X_{2}}{I-n_{1}} \frac{\partial n_{1}}{\partial Z_{2}}=0 \\
& \frac{\partial W_{2}}{\partial S_{21}}=g_{X}^{1}\left[\frac{-1}{I-n_{1}}-\frac{F_{2}-X_{2}}{I-n_{1}} \frac{\partial n_{1}}{\partial S_{21}}\right] \leq 0 \\
& S_{21} \geq 0, \text { and } S_{21} \frac{\partial W_{2}}{\partial S_{21}}=0 .
\end{aligned}
$$

Now,

$$
\frac{\partial n_{1}}{\partial Z_{2}}=\frac{1}{T}\left[g_{Z}^{n_{1}}-\frac{g_{X}^{n_{1}}}{I-n_{1}}\right]
$$

and

$$
\frac{\partial n_{1}}{\partial S_{21}}=-\frac{\partial n_{1}}{\partial S_{12}}
$$

Substituting for $\frac{\partial n_{1}}{\partial Z_{2}}$ from (XXIII) into (XXI), we get the Samuelson condition for region 2, while substituting for $\frac{\partial n_{1}}{\partial S_{21}}$ from (XXIV) and (XVII) into (XXII), we get

$$
\left(F_{1}-X_{1}\right)-\left(F_{2}-X_{2}\right) \leq \frac{8_{n}^{n} 1 n_{1}}{U_{X}\left(X_{1}, Z_{1}\right)}
$$

Note that (XVIII) and (XXV) give us (XII). Thus all Nash equilibria involve (XII) and Samuelson public good provision in each region, and are therefore efficient. We have done two things: the results of the main text are extended to local public good provision for the case where the marginal rate of substitution between private and public goods does not depend on $\mathrm{n}$; and second, if one removes public goods from the above analysis, it is clear that the results of the main text are extended to the most general specification for the utility functions. 


\section{References}

Boadway, R.W., 1982, "On the Method of Taxation and the Provision of Local Public Goods: Comment", American Economic Review 72, 846-851.

Boadway, R.W., and F. Flatters, 1982, "Efficiency and Equalization Payments in a Federal System of Government: A Synthesis and Extension of Recent Results," Canadian Journal of Economics 15, 613-633.

Boadway, R.W., and D.E. Wildasin, 1984, Public Sector Economics, 2nd Edition. Boston: Little, Brown.

Buchanan, J.M., and C.J. Goetz, 1972, "Efficiency Limits of Fiscal Mobility: an Assessment of the Tiebout Model", Journal of Public Economics, 1, 25-43.

DePalma, A. and Y.Y. Papageorgiou, 1988, "Heterogeneity in Tastes and Urban Structure," Region Science and Urban Economics, 18, 37-56.

Flatters, F., V. Henderson, and P. Mieszkowski, 1974, "Public Goods Efficiency and Regional Fiscal Equalization", Journal of Public Economics 3, 99-112.

Myers, G., 1990, "Optimality, Free Mobility, and the Regional Authority in a Federation", Forthcoming, Journal of Public Economics.

Starrett, D.A., 1980, "On the Method of Taxation and the Provision of Local Public Goods", American Economic Review 70, 380-392.

Starrett, D.A., 1982, "On the Method of Taxation and the Provision of Local Public Goods: Reply", American Economic Review 72, 852-853.

Stiglitz, J.E., 1977, "The Theory of Local Public Goods", in M. Feldstein and R.P. Inman, eds., The Economics of Public Services, (Macmillan, London), 247-333.

Wildasin, D.E., 1980, "Locational Efficiency in a Federal System", Regional Science and Urban Economics 10, 453-471.

Wildasin, D.E., 1986, Urban Public Finance, New York: Harwood Academic Publishers. Wildasin, D.E., 1987, "Theoretical Analysis of Local Public Economics," in E.S. Mills, Handbook of Urban and Regional Economics: Volume 2, Urban Economics (Amsterdam: North Holland), 429-476. 